\title{
The Mechanism Behind The Promotive Effect of Foliar Application of 5-Aminolevulinic Acid (ALA) in Tomato Plants Under Salt Stress
}

\author{
Afnan Freije*, Kareema Saleh, Sakina Islam, Mariam Al-Mannai \\ Department of Biology, College of Science, University of Bahrain, Sakhir Campus, P. O. Box \\ 32038, Kingdom of Bahrain \\ Corresponding author*: Afnan Freije \\ afreije@uob.edu.bh
}

\begin{abstract}
The effect of foliar ALA application on the internal ALA concentration in tomato plants grown in soil containing high levels of $\mathrm{NaCl}$ was investigated. Six week old plants were treated with 100,50 , and $25 \mathrm{mmol} / \mathrm{L} \mathrm{NaCl}$ on a weekly basis and they were simultaneously treated with 5ALA at a concentration of $5 \%$ by foliar spray. The effect of foliar ALA application on plant growth, chlorophyll contents and internal ALA concentration was studied. The internal ALA shoot concentrations ranged between $27.50 \pm 2.12$ and $34.35 \pm 1.48 \mathrm{mg} \mathrm{g}^{-1} \mathrm{dry}$ weight with no significant difference $(p<0.05)$ recorded between plants treated with $\mathrm{NaCl}$ alone and those treated with both $\mathrm{NaCl}$ and ALA. The concentrations of chlorophyll $a$ and $b$ were elevated only in tomato plants treated with $\mathrm{NaCl}$ and $\mathrm{ALA}$, whereas their levels decreased in plants treated with $\mathrm{NaCl}$ only. An adverse significant effect $(p<0.05)$ of salinity stress was recorded on plants length, number of leaves, shoot and root fresh and dry weight. However, no significant difference $(p<0.05)$ was observed in plants treated with $\mathrm{NaCl}$ alone with those treated with $\mathrm{NaCl}$ plus ALA in comparison to the control. The results of the present study suggested that foliar ALA treatment had no effect on the $\mathrm{Na}$ and $\mathrm{Cl}$ uptake, the internal ALA concentration, and had no role in adverting the effects of salinity on plant growth. The present study has proven that foliar ALA is directly used by the plant for the synthesis of chlorophyll in order to increase the photosynthetic rate and thus to help tomato plants to survive the salinity stress.
\end{abstract}

Key words: ALA, Chlorophyll, Lycopersicon esculentum, Salinity Stress, Tomato.

Date of Publication: 2018-08-30

DOI: https://doi.org/10.24297/jaa.v8i1.7498

ISSN: 2349-0837

Volume: 08 Issue: 01

Journal: Journal of Advances in Agriculture

Website: https://cirworld.com

This work is licensed under a Creative Commons Attribution 4.0 International License 


\section{Introduction}

5- aminolevulinic acid (ALA) is a natural amino acid that plays a role in the improvement of many physiological and biochemical characteristics of plants such as the improvement of plants tolerance to stress including cold and hot temperatures, salinity, and water scarcity (Hotta et al., 1998; Watanabe et al., 2000; Balestrasse et al., 2010; Al-Qureshi and Awad, 2011).

ALA formation is the first step in the biosynthesis of chlorophyll. Two molecules of ALA are condensed to form porphobilinogen (PBG), a unique single pyrrole structure. Subsequently, four molecules of PBG then condense to form a large ring (Uroporphyrinogen III) which is oxidized to form protoporphyrin IX. This pathway will further branches depending on the type of metal added to the porphyrin centre. If magnesium is inserted, then additional steps are needed to convert the molecule into chlorophyll (Taiz and Zeiger, 2002).

Several studies have demonstrated the promotive effect of ALA on the photosynthetic rate and chlorophyll contents in a number of plants. The chlorophyll content increased significantly by $21-30.1 \%$ while $\mathrm{CO}_{2}$ concentration decreased after ALA treatment in Kudzu plant species (Xu et al., 2010). Several studies on date palms (Al-Khateeb et al., 2006), horseradish, rice seedlings (Hotta et al., 1997), and lettuce (Xu et al., 2012) have also demonstrated similar results. Foliar application of ALA has also enhanced the chlorophyll content; photosynthetic rate in Pakchoi leaves (Memon et al., 2009). These results coincided with the study of Tanaka et al. (1993) which suggested that exogenous treatment with ALA may result in higher level of chlorophyll a which is a perquisite for chlorophyll $b$ formation (Wang et al., 2005; Awad, 2008).

Many plants live under salt stress condition in different regions of the world. Salt stress can adversely affect various plant processes such as reduction in the seed germination, yield, and the photosynthetic rate (Wang et al., 2001; Perveen et al., 2010). The positive effect of the liquid fertilizer PENTAKEEP which contains ALA on plant photosynthesis, growth, and stress resistance has been documented (Watanabe et al., 2000; Nishihara et al., 2003; Zsembeli et al., 2008). The foliar application of ALA plays an important role in reducing the salt-induced effects in many plants such as the Pakchoi (Brassica campestris) (Memon et al., 2009), spinach (Spinacia oleracea) (Nishihara et al., 2003), cotton seedlings (Wantanabe et al., 2000), and sunflower (Helianthus annus L) (Akram et al., 2012).

ALA helps in regulating the physiological processes which are associated with plant growth under salt stress (Zhao et al., 2014) such as improving the reactive oxygen species by scavenging (Nishihara et al., 2003; Akram et al., 2012), regulating the $\mathrm{NA}^{+}$uptake (Watanabe et al., 2000), improving seed germination (Hotta et al., 1997a, b), improving the photosynthesis (Wang et al., 2008), enhancing photosynthetic capacity(Zhao et al., 2014), and controlling aquaporin expression (Zhao et al., 2015). 
Tomato is a glycophyte plant that has been classified as a moderate salt-tolerant crop (Maas, 1986) using an exclusion strategy that restrict the excessive transport of $\mathrm{Na}$ and $\mathrm{Cl}$ to the roots as well as from roots to shoots of plants grown in saline substrates (Bergmann, 1992; Marschner, 1995).Tomato is an important crop facing a serious constraint when grown in areas with optimal climate for tomato cultivation however suffering from salinization of soil which is considered as a serious problem facing many countries specially in arid and semiarid areas (Yurtseven et al., 2005; Abdel Latef, 2010).

Most studies available today have investigated the importance of ALA external application in reducing the salt-induced effects in many plants. However, the present study is a first attempt to examine the effect of salinity on ALA internal contents in tomato plants treated with foliar ALA and therefore its correlation to salt tolerance. To our knowledge, no research has investigated the interactive effects of external ALA application with internal ALA concentration under saline conditions in any plant including tomato.

\section{Materials and Methods}

\section{Plant material and growth conditions}

Tomato seeds (Lycopersicon esculentum L. cV. Vanessa, F1) were sowed in Bio-Mix Peat Potting Substratum (Jiffy Products International BV, Holland) in plastic tray. Bio-Mix Peat Potting Substratum properties were (organic matter $\geq 85 \%, \mathrm{Ca} \geq 5 \%, \mathrm{pH} 3.5-6.5, \mathrm{Na} \leq$ $250 \mathrm{mg} / \mathrm{L}$ ). Four weeks old germinated seeds were transferred into pots filled with Bio-Mix Peat Potting Substratum and were kept in a greenhouse under natural light conditions at an average temperature of $20-35^{\circ} \mathrm{C}$ during the experiment span of time at the University of Bahrain, College of Science, Sakhir campus. The experiment was conducted during the period from 25 October 2016 till 8 January 2017.

Six week old plants were treated with 100,50 , and $25 \mathrm{mmol} / \mathrm{L} \mathrm{NaCl}$ on a weekly basis and they were simultaneously treated with PENTAKEEP® super EC Fertilizer containing 5-ALA provided by Cosmo Seiwa Agriculture CO., LTD, Japan at a concentration of $5 \%$ by foliar spray. The upper and lower leaf surface were sprayed until wetted by hand-held sprayer due to the fact that the absorption of lower leaf surface is more rapid and effective (Hull et al., 1975). The concentrations of $\mathrm{NaCl}$ were selected based on various salinity-induced studies in different plants (Watanabe et al., 2000; Tari et al., 2002; Nishihara et al., 2003; Naeem et al., 2012; Zhang et al., 2013). The same salt treatment was repeated on another set of plants without the use of the ALA foliar application. In the control treatment, distilled water was used instead of salt solution. Each treatment was replicated four times and plants were harvested after 10 weeks of salt and ALA treatments.

Plants were washed with distilled water, blotted to dry, divided into shoots and roots, and weighed. Plants height, and number of leaves were measured and counted. Shoots and roots were then placed in an oven at $60^{\circ} \mathrm{C}$ to dry until reaching a constant weight and their dry weight was then recorded. Shoot and root samples were mechanically grinded to fine power, kept in closed glass bottles, and stored in a dry dark and cool place until analysis. 


\section{Chlorophyll determination}

Two grams of leaf samples were used for each replicate/treatment to determine the concentrations of chlorophyll a and b. Chlorophyll contents were extracted using $10 \mathrm{~mL}$ acetone (90\%). The extracts were then centrifuged for 10 minutes at $4000 \times \mathrm{g}$, and chlorophyll $\mathrm{a}$ and $\mathrm{b}$ were measured by spectrophotometer (Perkin Elmer Lambda XLS), and calculated using the appropriate equations following the UNESCO protocol (Vohra, 1966).

\section{ALA extraction and analysis}

ALA extraction was carried out following the procedure of Kolossov and Rebeiz (2005) with some modifications as described by Freije and Alkhuzai (2015). One gram of the powdered plant leaves with a total of four replicate from each specimen/treatment were used for the ALA analysis. Fluorometric measurement of ALA was performed on the extracted samples according to the method of Lee et al. (2004) with some modifications as described by Freije and Alkhuzai (2015).

\section{Statistical analysis}

The obtained data were statistical analyzed using the Minitab 16. One way analysis of variance was used to test the difference in the means of height, leaves, shoot wet, shoot dry weight, shoot ALA, chlorophyll a and b, root wet, root dry weight among the different treatments of water, water plus salt, and water plus salt plus ALA. Independent samples to test was also performed to test if there were significant differences between the presence and absence of ALA. Results were presented in 4 replicates of mean values and standard deviations $( \pm S D)$. A value of $P<0.05$ was considered statistically significant.

\section{Results and Discussion}

The effect of different salt treatment alone and in combination with foliar ALA application on plant growth in terms of height, number of leaves, shoot and root fresh and dry weight is presented in Table 1 . Dunette test was used to find out the significant level of different salt treatments alone and in combination with ALA in comparison to control plants (Table 2). A significant inhibitory effect $(p<0.05)$ was observed in plants subjected to salinity stress and salinity plus ALA treatments as compared to their respective control. This decrease was higher in plants grown under $50 \mathrm{mmol} / \mathrm{L} \mathrm{NaCl}$ condition compared to control groups; while the growth of all plants treated with $100 \mathrm{mmol} / \mathrm{L} \mathrm{NaCl}$ was terminated after 10 days of salt treatment. Moreover, no significant difference was recorded in any growth parameters measured between plants treated with $\mathrm{NaCl}$ alone and those treated with both $\mathrm{NaCl}$ and ALA. 
Table 1: Effects of salinity and ALA on shoot length, number of leaves, and biomass of Lycopersicon esculentum L. plants. Figures in the same column having the same superscript are not significantly different at $p<0.05$.

\begin{tabular}{|c|c|c|c|c|c|c|c|}
\hline Treatment & Length $(\mathrm{cm})$ & $\begin{array}{l}\text { No. } \\
\text { leaves }\end{array}$ & of & $\begin{array}{l}\text { Shoot } \\
\text { fresh } \\
\text { weight }\end{array}$ & $\begin{array}{l}\text { Shoot } \\
\text { dry weight } \\
\text { (g) }\end{array}$ & $\begin{array}{l}\text { Root } \\
\text { fresh } \\
\text { weight }\end{array}$ & $\begin{array}{l}\text { Root } \\
\text { dry weight } \\
\text { (g) }\end{array}$ \\
\hline
\end{tabular}
(g)
(g)

$\begin{array}{lllllll}\text { Control }\left(\mathrm{H}_{2} \mathrm{O}\right) & 26.30 \pm 2.12^{\mathrm{a}} & 9.00 \pm 0.00^{\mathrm{a}} & 19.97 \pm 0.21^{\mathrm{a}} & 2.16 \pm 0.11^{\mathrm{a}} & 3.33 \pm 0.82^{\mathrm{a}} & 0.29 \pm 0.04^{\mathrm{a}} \\ 50 \mathrm{mmol} / \mathrm{L} \mathrm{NaCl} & 12.35 \pm 0.49^{\mathrm{b}} & 5.50 \pm 0.71^{\mathrm{b}} & 4.45 \pm 0.43^{\mathrm{b}} & 0.75 \pm 0.07^{\mathrm{b}} & 0.83 \pm 0.11^{\mathrm{b}} & 0.03 \pm 0.01^{\mathrm{b}} \\ & & & & & & \\ 25 \mathrm{mmol} / \mathrm{L} \mathrm{NaCl} & 17.15 \pm 1.48^{\mathrm{c}} & 8.50 \pm 0.71^{\mathrm{c}} & 12.10 \pm 0.49^{\mathrm{c}} & 1.29 \pm 0.01^{\mathrm{c}} & 1.11 \pm 0.21^{\mathrm{c}} & 0.07 \pm 0.05^{\mathrm{c}} \\ \text { Control }\left(\mathrm{H}_{2} \mathrm{O}\right)+ & & & & \\ \text { ALA } & 27.15 \pm 0.64^{\mathrm{a}} & 9.50 \pm 0.71^{\mathrm{a}} & 20.66 \pm 4.91^{\mathrm{a}} & 2.23 \pm 0.61^{\mathrm{a}} & 3.51 \pm 0.36^{\mathrm{a}} & 0.34 \pm 0.04^{\mathrm{a}}\end{array}$

$50 \mathrm{mmol} / \mathrm{L} \mathrm{NaCl}+$
ALA
$13.10 \pm 0.14^{b} \quad 5.50 \pm 0.71^{b}$
$4.31 \pm 0.52^{b}$
$0.82 \pm 0.19^{b} \quad 0.89 \pm 0.06^{b}$
$0.03 \pm 0.01^{\mathrm{b}}$

$25 \mathrm{mmol} / \mathrm{L} \mathrm{NaCl}+$

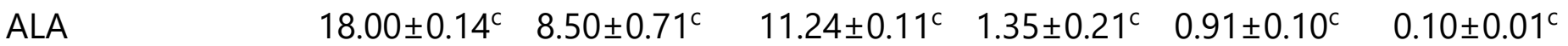

Table 2: Correlation and interaction analysis between ALA and salt treatment and shoot length, number of leaves, biomass, photosynthetic pigments and ALA concentrations in Lycopersicon esculentum $\mathrm{L}$.

\begin{tabular}{lll}
\hline Correlation parameter & $\begin{array}{c}\text { Significant level } \\
(\mathrm{p})\end{array}$ & $\begin{array}{l}\text { Correlation/ } \\
\text { interaction }\end{array}$ \\
\hline Length and salt treatment & 0.000 & Correlation \\
Length and ALA treatment & 0.250 & No correlation \\
Length, ALA and salt treatment interactions & 0.997 & No interaction \\
No. of leaves and salt treatment & 0.000 & Correlation \\
No. of leaves and ALA treatment & 0.670 & No correlation \\
No. of leaves, ALA and salt treatment interactions & 0.824 & No interaction \\
Shoot wet weight and salt treatments & 0.000 & Correlation \\
Shoot wet weight and ALA treatment & 0.935 & No correlation \\
Shoot wet weight, ALA and salt treatment interactions & 0.867 & No interaction \\
Shoot dry weight and salt treatments & 0.001 & Correlation \\
Shoot dry weight and ALA treatment & 0.234 & No correlation \\
Shoot dry weight, ALA and salt treatment interactions & 0.485 & No interaction \\
Shoot ALA level and salt treatment & 0.002 & Correlation
\end{tabular}


Shoot ALA level and ALA treatment

Shoot ALA level, ALA and salt treatment interactions

Chlorophyll a content and salt treatment

Chlorophyll a content and ALA treatment

Chlorophyll a content, ALA and salt treatment interactions

Chlorophyll b content and salt treatment

Chlorophyll b content and ALA treatment

Chlorophyll b content, ALA and salt treatment interactions

Chlorophyll c content and salt treatment

Chlorophyll c content and ALA treatment

Chlorophyll b content, ALA and salt treatment interactions

Root wet weight and salt treatments

Root wet weight and ALA treatment

Root wet weight, ALA and salt treatment interactions

Root dry weight and salt treatments

Root dry weight and ALA treatment

Root dry weight, ALA and salt treatment interactions
0.831

0.484

0.016

0.000

0.000

0.878

0.010

0.024

0.000

0.000

0.000

0.000

0.359

0.455

0.000

0.208

0.600
No correlation

No interaction

Correlation

Correlation

Interaction

No correlation

Correlation

Interaction

Correlation

Correlation

Interaction

Correlation

No correlation

No interaction

Correlation

No correlation

No interaction

The effect of different salt treatment alone and in combination with foliar ALA application on the photosynthetic pigments Chlorophyll $a$ and $b$ is shown in Table 3. All photosynthetic pigments investigated were significantly decreased $(p<0.05)$ with increasing $\mathrm{NaCl}$ levels in comparison to the control plants. However, a significant increase $(p<0.05)$ in all photosynthetic pigments studied was recorded in plants treated with ALA in combination with $\mathrm{NaCl}$; whereas no significant difference in the photosynthetic pigments content was recorded in plants treated with ALA alone compared with control plants as shown in Table 2.

Table 3: Effects of salinity and ALA on photosynthetic pigments and ALA concentrations in Lycopersicon esculentum L. leaves.

\begin{tabular}{llll}
\hline Treatment & $\begin{array}{l}\text { Chlorophyll } \\
\mathrm{a}(\mu \mathrm{g} / \mathrm{L})\end{array}$ & $\begin{array}{l}\text { Chlorophyll b } \\
(\mu \mathrm{g} / \mathrm{L})\end{array}$ & $\begin{array}{c}\text { Shoot ALA } \\
\mu \mathrm{g} \mathrm{g}^{-1} \text { dry weight }\end{array}$ \\
\hline Control $\left(\mathrm{H}_{2} \mathrm{O}\right)$ & $14.80 \pm 1.03$ & $5.51 \pm 0.98$ & $28.75 \pm 1.77$ \\
& & & \\
$50 \mathrm{mmol} / \mathrm{L} \mathrm{NaCl}$ & $9.09 \pm 0.71$ & $3.28 \pm 0.49$ & $33.15 \pm 0.92$ \\
& & & \\
$25 \mathrm{mmol} / \mathrm{L} \mathrm{NaCl}$ & $9.62 \pm 0.01$ & $3.52 \pm 0.15$ & $33.10 \pm 0.99$ \\
& $14.33 \pm 0.07$ & $5.73 \pm 0.80$ & $27.50 \pm 2.12$
\end{tabular}




$$
\begin{array}{llll}
\text { Control }\left(\mathrm{H}_{2} \mathrm{O}\right)+\mathrm{ALA} & & & \\
& & & \\
50 \mathrm{mmol} / \mathrm{L} \mathrm{NaCl}+\mathrm{ALA} & 16.44 \pm 0.37 & 6.82 \pm 1.53 & 33.70 \pm 0.71 \\
& & & \\
25 \mathrm{mmol} / \mathrm{L} \mathrm{NaCl}+\mathrm{ALA} & 18.81 \pm 0.08 & 6.14 \pm 0.01 & 34.35 \pm 1.48 \\
\hline
\end{array}
$$

ALA concentrations in plant shoots treated with $\mathrm{NaCl}$ alone and in combination with ALA showed no significant difference in comparison to control plants (Tables 2 and 3). Similarly, ALA foliar treatment had no significant effect on the internal ALA concentration in all types of treatment nor on the photosynthetic pigments in the control plants.

The adverse effect of salinity on different types of plants including tomato has been fully elucidated in several studies (Naeem et al., 2012; Zhang et al., 2013; Zhao et al., 2014, 2015). The result of the present study is consistent with the previous studies; it has shown a significant decrease in tomato plants length, number of leaves, shoot and root wet and dry weight when treated with different concentrations of $\mathrm{NaCl}$.

On the other hand, the promotive effect of ALA foliar application on the photosynthetic rate and chlorophyll contents have been elucidated in plants under different types of stress such water stress (Luo et al., 2014), cold stress (Balestrasse et al., 2010) hot arid climate (Al-Qurashi et al., 2011), dry conditions (Al-Thabet, 2006), as well as salt stress(Xu et al., 2011; Zhao et al., 2014, 2015).

\section{Conclusion}

The current study has focused on the internal concentration of ALA and chlorophyll content in tomato plants grown under salt stress in comparison to no stress. The result of the current study has revealed a promotive effect of ALA foliar application only in plants grown under salt stress condition. A significant increase in the chlorophyll $a$ and $b$ contents was only seen in tomato plants treated with 25 and $50 \mathrm{mmol} / \mathrm{L} \mathrm{NaCl}$ as well as ALA. However, the ALA foliar application had no significant effect on the photosynthetic pigments in the control plants. Furthermore, internal ALA contents were not affected by the foliar application of ALA in all plant samples including salt stressed.

The results of the present study support the findings of the previous study of Freije and Alkhuzai (2015) which has shown that the internal ALA concentration is specific in plants living at their natural habitats and is mainly used to maintain plants' specific chlorophyll content and photosynthetic parameters; whereas the external ALA application is directly converted to chlorophyll by plants and thus enhance plants adaptation to environmental stresses including salt stress.

\section{Acknowledgements}

The authors are grateful to the Department of Biology, College of Science, University of Bahrain where the study was conducted and financially supported. 


\section{References}

[1] Abdel Latef A.A. 2010. Changes of antioxidative enzymes in salinity tolerance Among different wheat cultivars. Cereal Res. Comm., 38: 43-55.

[2] Adler P.R. and Wilcor G.E. 1987. Salt stress mechanical stress or chloromequat Chloride effects on morphology and growth recovery of hydroponic tomato transplants. J. Am. Soc. Hort. Sci., 112: 22-25.

[3] Akram N.A., Ashraf M. and Al-Qurainy F. 2012. Aminolevulinic acid induced some key physiological attributes and activities of antioxidant enzymes in sunflower Helianthus annus L plants under saline regimes. Sci. Hort., 142: 143-148

[4] Al-Qureshi A.D. and Awad M.A. 2011. 5-Aminolevulinic acid increases tree yield and improves fruit quality of Rabia and Sukkariat-Yanbo date palm cultivars under hot climate. Sci. Hort., 129: 441-448.

[5] Balestrasse K.B., Tomaro M.L., Batle A. and Noriega G.O. 2010. The role of 5-aminolevulinic acid in the response to cold stress in soybean plants. Phytochemistry, 71: 2038-2045.

[6] Bergmann W. 1992. Nutritional disorders of plants. Gustav Fisher Verlag, Stutgart.

[7] Freije A.M. and Alkhuzai J.A. 2015. Is 5-aminolevulinic acid concentration in plants related to soil salinity? A test with 17 native species of Bahrain. J. Arid. Environ., 119: 56-60.

[8] He Z., He C., Zhang Z. , Zou Z. and Wang H. 2007. Changes of antioxidative enzymes and cell membrane osmosis in tomato colonized by arbuscular mycorrhizae under $\mathrm{NaCl}$ stress Colloids Surf B. Biointerfaces, 59: 128-133.

[9] Hotta Y., Tanaka T., Takaoka H., Takeuchi Y. and Konnai M. 1997 a. Promotive effects of 5-aminolevulinic acid on the yield of several crops. Plant Growth Regul., 22: 109-114.

[10] Hotta Y., Tanaka T., Takaoka H., Takeuchi Y. and Konnai M. 1997b. New Physiological effects of 5-aminolevulinic acid in plants: the increase of photosynthesis chlorophyll content and plant growth. Biosci. Biotech. Biochem., 61: 2025-2028.

[11] Hotta, Y., Tanaka T., Bingshan L., Takeuchi Y. and Konnai M. 1998. Improvement of cold resistance in rice seedlings by 5 -aminolevulinic acid. J. Pesticide, 23: 29-33.

[12] Hull H.M., Morton H.L. and Wharrie J.R. 1975. Environmental influence on cuticle development and resultant foliar penetration. Bot. Rev. 41: 421-451.

[13] Kolossov V.L. and Rebeiz C.A. 2005. Chloroplast biogenesis: Detection of $\delta$ aminolevulinic acid esterase activity in higher plant and insect tissues. Pestic. Biochem. Physiol., 83: 9-20. 
[14] Lee C., Qiao X., Goeger D.E. and Anderson K.E. 2004. Fluorometric measurement of 5aminolevulinic acid in serum. Clin. Chim. Acta., 3471-2 :183-188.

[15] Lou Y., Zhao X. and Qu H. 2014. Photosynthetic performance and growth traits in Pennisetum centrasiaticum exposed to drought and rewatering under different soil nutrient regimes. Acta. Physiol., 36(2): 381. DOI: 10.1007/s11738-013-1419-2.

[16] Maas E.V. 1986. Salt tolerance of plants. Appl. Agri.c Res., 1: 12-26.

[17] Marschner H. 1995. Mineral Nutrition of Higher Plants, 2nd ed. Academic Press. New York.

[18] Memon S.A., Hou X., Wang L. and Li Y.2009. Promotive effects of 5-aminolevulinic acid on chlorophyll antioxidative enzymes and photosynthesis of Packchoi. Acta. Physiol. Plant, 31: 51-57.

[19] Naeem M.S., Jin Z.L., Wan G.L., Liu D., Liu H.B., Yoneyama K. and Zhou W.J. 2010. 5Aminolevulinic acid improves photosynthetic gas exchange capacity and ion uptake under salinity stress in oilseed rape (Brassica napus L). Plant Soil., 332: 405-415.

[20] Naeem M.S., Warusawitharana H., Liu H., Liu D., Ahmad R., Waraich E.A., Xu L. and Zhou W. 2012. 5-Aminolevulinic acid alleviates the salinity-induced changes in Brassica napus as revealed by the ultrastructural study of chloroplast. Plant Physiol. Biochem., 57: 84-92.

[21] Nishihara E., Kondo K., Parvez M.M., Takahashi K., Watanabe K. and Tanaka K. 2003. Role of 5-aminolevulinic acid ALA on active oxygen- scavenging system in $\mathrm{NaCl}$-treated spinach (Spinacia oleracea). J. Plant. Physiol., 160: 1085-1091.

[22] Omar M.A., Omar F.A. and Samarrai S.M. 1982. Effect of different soil treatments on tomato plants grown in Wadi Fatima soil B Effect of salinity treatments. Technical Report, Faculty of Meteorol-Environ and Arid Land Agric.

[23] Perveen S., Shahbaz M. and Ashraf M. 2010. Regulation in gas exchange and quantum yield of photosystem II PSII in salt-stressed and non-stressed wheat plants raised from seed treated with triacontanol. Pak. J. Bot., 42: 3073-3081.

[24] Satti S.M. and Al-Yahyai R.A. 1995. Salinity tolerance in tomato: Implications of potassium calcium and phosphorus. Soil Sci. Plant Anal., 26: 2749-2760.

[25] Tari I., Csiszár J., Szalai G., Horváth F., Pécsváradi A. , Kiss G., Szepesi A., Szabó M. and Erdei L. 2002. Acclimation of tomato plants to salinity stress after a salicylic acid pretreatment. Acta Biol. Szeged., 463: 55-56.

[26] Taiz L. and Zeiger E. 2002. Plant Physiology (3rd edition) Sinauer Associates, Inc. Sunderland. pp.611-613. 
[27] Vohra F.C. 1966. Determination of photosynthetic pigment in seawater Monographs on Oceanographic methodology. UNESCO. France.

[28] Watanabe K., Tanaka T. , Hotta Y., Kuramochi H. and Takeuchi Y. 2000. Improving salt tolerance of cotton seedlings with 5-aminolevulinic acid. Plant Growth Regul., 32: 99-103.

[29] Wang Y., Mopper S. and Hasenstein K.H. 2001. Effects of salinity on endogenous ABA IAA JA and SA in Iris hexagona. J. Chem. Ecol., 27: 327-342.

[30] Wang L.J., Jiang W.B., Liu H., Liu W.Q., Kang L. and Hou X.L. 2005. Promotion by 5aminolevulinic acid of germination of Pakchoi Brassica campestris seeds under salt stress. J. Integr. Plant Biol., 479: 1084-1091.

[31] Wang Y., Zhu J., Zheng F., Cheng H. , Chang J., Xu F. and Cheng S. 2008. Effect of 5aminolevulinic acid on photosynthesis and flavonoids content of Ginkgo biloba leaves. In: Tang K, Huang D Wang S (Eds.), Advances in Horticulture vol VIII, Shanghai Jiaotong University Press, Shanghai pp. 651- 654.

[32] Xu F., Cheng S., Zhu J., Zhang W. and Wang Y. 2011. Effects of 5-Aminolevulinic Acid on Chlorophyll Photosynthesis Soluble Sugar and Flavonoids of Ginkgo biloba. Not. Bot. Hort., 391: 41-47.

[33] Youssef T. and Awad M.A. 2008. Mechanisms of enhancing phtotosynthtic gas exchange in date palm seedlings phoenix dactylifera $L$ under salinity stress by 5 -aminlevulinc acid based fertilizer. J. Plant Growth Regul., 27: 1-9.

[34] Yurtseven E., Kesmez G.D. and Ünlükara F.A. 2005.The effects of water salinity and potassium levels on yield fruit quality and water consumption of a native central Anatolian tomato species Lycopersicon esculentum. Agric. Water Manage., 78: 128-135.

[35] Zhang Z.J., Li H.Z., Zhou W.J., Takeuchi Y. and Yoneyama K.2006. Effect of 5aminolevulinic acid on development and salt tolerance of potato Solanum tubersum microtubers in vitro. Plant Growth Regul., 49: 27-34.

[36] Zhang C.P., Li Y.C., Yuan F.G., Hu S.J., Liu H.Y. and He P.2013. Role of 5-aminolevulinic acid in the salinity stress response of the seeds and seedlings of the medicinal plant Cassia obtusifolia L. Bot. Stud., 54: 18. http://wwwas-botanicalstudiescom/content/54/1/18.

[37] Zsembeli J., Kovacs G. and Muranyi A. 2008. Effect of PENTAKEEP-V on the evapotranspiration and yield of 3 Sorghum hybrids monitored in precision weighing lysimeters. Cereal Res. Commun., 36: 795-798 .

[38] Zhoa Y., Yan F., Hu L.P., Zhou X.T. and Zou Z.R. 2014. Effect of 5-aminolevulinic acid on photosynthetic characteristics of tomato seedlings under $\mathrm{NaCl}$ stress. Ying. Yong. Sheng. Tai. Xue. Bao., 25(10): 2919-2926. 
[39] Zhoa Y., Yan F., Hu L.P., Zhou X.T., Zou Z.R. and Cui L.R. 2015. Effect of exogenous 5aminolevulinic acid on photosynthesis, stomatal conductance, transpiration rate, and PIP gene expression of tomato seedlings subject to salinity stress. Genet. Mol. Res., 14(2): 64016412. 